(c) 2011 IEEE. Personal use of this material is permitted. Permission from IEEE must be obtained for all other uses, in any current or future media, including reprinting/republishing this material for advertising or promotional purposes, creating new collective works, for resale or redistribution to servers or lists, or reuse of any copyrighted component of this work in other works. 


\title{
Assessment of workplace diesel exhaust exposure and health effects
}

\author{
Le Jian*, Phillip Meyerkort, Janis Jansz \\ Curtin Health Innovation Research Institute, \\ Curtin University \\ Perth, Australia \\ *Email: l.jian@curtin.edu.au
}

\begin{abstract}
Diesel exhaust can pose a significant health risk on exposure populations and workplace can be a significant source of exposure to diesel exhaust. Because of its complex compositions and the delay of advanced technology in exposure assessment, diesel exhaust exposure assessment at workplace in relation to its health effects is understudied. More efforts are needed to clarify exposure levels that may result in adverse health effects, in particular, chronic health effects.
\end{abstract}

\section{Keywords-diesel exhaust; health effects; workplace}

\section{INTRODUCTION}

Diesel exhaust has been classified as 'probably carcinogenic to humans' [1-2], and has been associated with respiratory, allergic, cardiovascular and reproductive effects in both animal and human studies [3]. The potential effects of ambient diesel exhaust exposure is of great interest, especially as the use of diesel engine technology continues to grow across the world, with the recognition that diesel engine technology can reduce greenhouse gas emissions, compared to other fuels [4]. The acute and chronic effects of diesel exhaust exposure in Australian working populations remains relatively under studied.

Hazardous levels of diesel exhaust can be found in occupations ranging from mining to driving diesel-fuelled trucks or forklifts [5]. Durability and fuel efficiency have lead to an increase in the use of diesel engines. On road engines, mainly vehicles, and non road engines, including locomotives, marine vessels, and heavy duty equipment represent significant sources of occupational exposure to diesel exhausts. The longevity of diesel engines is an important factor to understand including past, current and projected exposures to diesel exhaust as older engines are subject to less stringent regulations and may remain in use for several decades after their manufacture [4].

Exposure to diesel exhaust has been associated with premature death from heart and/or lung disease in American studies [6] while in Australia, the dieses burden of workers exposed to diesel exhaust is relatively under studied. Majority published epidemiological studies used job classification as exposure surrogates. An understanding of the exposure levels and related disease burdens in workers exposed to diesel exhaust will assist in early identification of chronic health conditions and in developing appropriate workplace risk control measures.

\section{DIESEL EXHAUST}

Diesel exhaust is a complex mixture of up to hundreds of gaseous and particulate components formed from the complete and incomplete combustion of organic compounds. Gaseous components include carbon dioxide, oxygen, nitrogen, water vapour, carbon monoxide, nitrogen compounds, sulfur compounds and low molecular weight hydrocarbons [7]. Toxic gaseous components include the aldehydes, benzene, butadiene and polycyclic aromatic hydrocarbons (PAHs) and nitro-PAHs. Diesel exhausts vary significantly in chemical composition and particle size between different engine types (heavy duty vs. light duty), engine operating conditions (idle, accelerate, decelerate) and fuel formulations (high/low sulfur fuels) [8]. Although advances in technology have seen a reduction in the amounts of toxic emissions, toxicologically relevant components (PAH, nitro PAH) persist [3].

After emission, diesel exhaust undergoes dilution, chemical and physical transformations, dispersion and transport into the atmosphere [9-10]. Once in the ambient environment, diesel exhaust undergoes ageing, atmospheric transformation processes, affecting the organics present and altering particle size. The health effects of these transformations are unclear as some processes produce less toxic forms, whereas others can increase toxicity. Diesel exhaust reacts with sunlight, hydroxyl radicals, ozone, hydroperoxyl radicals, nitrate radicals and nitrous acid and sulfuric acid species; the majority of constituents undergo oxidation; these are dependent on time of day and meteorological conditions [10-11]. The atmospheric lifetime of some compounds ranges from hours to days.

Diesel particulate matter (DPM) is directly emitted from diesel engines, as primary particulate matter, and can be formed from the gaseous compounds emitted by diesel engines, as secondary particulate matter [7]. Particulate matter (PM) is usually subdivided into PM10 (inhalable particles), PM2.5 (fine particles) and PM0.1 (ultra fine particles). The PM size generally represents different

Sponsors: Cancer Council of Western Australia \& Curtin University 
sources and display different physical and chemical properties, but the properties associated with toxicity are incompletely understood. The four main characteristics of DPM include a high proportion of elemental carbon; a large surface area associated with carbonaceous particles in the $0.2 \mu \mathrm{m}$ size range; polycyclic organic compounds adsorbed to particles; and $50-90 \%$ of the number of particles are ultrafine (<1um), with a mode of 20nm [12]. Particles are of particular concern as smaller particles have large surface area to which toxic components can be adsorbed. It has been suggested that new technology is associated with high proportion of nanoparticles [13].

\section{EXPOSURE TO DIESEL EXHAUST}

A recent review by Pronk et al.[5] reported literature on occupational uses of diesel engines and subsequent personal exposure to diesel exhausts. Over 10,000 assessments of elemental carbon, particulate matter, carbon monoxide and nitric oxides measurements were included; with $32 \%$ on road exposures; 68\% off road exposures (including 30\% mining and 15\% rail). Elemental carbon (EC) levels were most consistently reported in each study, and hence used for comparison between occupations.

Highest exposure levels were observed for enclosed underground work sites in which heavy equipment is used (including mining, mine maintenance, construction) $27-658 \mathrm{ug} / \mathrm{m}^{3}$ of EC. Intermediate exposure levels were observed in above ground semi enclosed areas in which smaller equipment was used (mechanics in workshop, workers on ferries) $<50 \mathrm{ug} / \mathrm{m}^{3}$ EC. Lowest levels were observed in roles where workers are in enclosed areas separated from the source (drivers, train crew) $<25 \mathrm{ug} / \mathrm{m}^{3}$ EC. The main determinants of exposure levels for enclosed situations were ventilation and exhaust after treatment devices [5].

Although this review brings together a wealth of information regarding exposure levels it is difficult to apply these levels to other situations, as no single constituent of diesel exhaust is considered a unique marker of exposure. Furthermore, assessing occupational exposures in epidemiological studies in general population is difficult. For chronic diseases, such as cancer, the relevant exposure periods are usually from decades ago, and relevant exposure measurements are not available. Exposures can also vary widely depending on individual work environments. The composition of diesel exhausts varies with engine technology, fuel type, operating conditions and emission control systems; all have which have changed over time.

\section{DIESEL EXHAUSTS COMPONENTS OF POSSIBLE BIOLOGICAL IMPACTS}

The major components of diesel exhaust, their atmospheric reaction products and biological impacts have been summarized in Table 1 by US EPA [10].
TABLE 1. MAJOR COMPONENTS OF DIESEL EXHAUST, ATMOSPHERIC REACTION PRODUCTS AND BIOLOGICAL IMPACTS. (ADAPTED FROM US EPA, 2002).

\begin{tabular}{|l|l|l|}
\hline \multicolumn{1}{|c|}{$\begin{array}{c}\text { Particle phase } \\
\text { components }\end{array}$} & \multicolumn{1}{|c|}{$\begin{array}{c}\text { Atmospheric } \\
\text { reaction products }\end{array}$} & \multicolumn{1}{|c|}{ Biological impact } \\
\hline Elemental carbon & - & $\begin{array}{l}\text { Nuclei adsorb organic } \\
\text { compounds; size } \\
\text { permits transport deep } \\
\text { into the lungs (alveoli) }\end{array}$ \\
\hline $\begin{array}{l}\text { Inorganic sulfate and } \\
\text { nitrate }\end{array}$ & - & $\begin{array}{l}\text { Respiratory tract } \\
\text { irritation }\end{array}$ \\
\hline $\begin{array}{l}\text { Hydrocarbons (C14 } \\
\text { - C35) }\end{array}$ & $\begin{array}{l}\text { Little information; } \\
\text { possibly aldehydes, } \\
\text { ketones, and alkyl } \\
\text { nitrates }\end{array}$ & Unknown \\
\hline $\begin{array}{l}\text { PAHs (e.g. pyrene, } \\
\text { benzo[a]pyrene) }\end{array}$ & $\begin{array}{l}\text { NitroPAHs and } \\
\text { nitroPAH lactones }\end{array}$ & $\begin{array}{l}\text { Larger PAHs are } \\
\text { major contributors of } \\
\text { carcinogens; } \\
\text { nitroPAHs are potent } \\
\text { mutagens and } \\
\text { carcinogens }\end{array}$ \\
\hline $\begin{array}{l}\text { NitroPAHs (e.g. } \\
\text { nitropyrenes) }\end{array}$ & $\begin{array}{l}\text { Hydroxylated nitro } \\
\text { derivatives }\end{array}$ & $\begin{array}{l}\text { Potent mutagens and } \\
\text { carcinogens }\end{array}$ \\
\hline
\end{tabular}

The components of diesel exhausts that represent a possible health concern are the particles (elemental carbon core), the organic compounds absorbed to the particles, and the organic compounds present in the gas phase [14].

\section{A. Particles}

Approximately $80-95 \%$ of diesel particulate matter is in the fine particle size range $(<2.5 \mu \mathrm{m})$, with a mean particle diameter of $0.2 \mu \mathrm{m}$ [7]. Particles with an aerodynamic diameter $>2.5 \mu \mathrm{m}$ tend to be retained in the upper respiratory tract, whereas those $<2.5 \mu \mathrm{m}$ are deposited in all areas, especially in the lower portions of the respiratory tract. Fine and ultra fine particles have a large surface area per gram mass which enables them to adsorb and transport inorganic and organic compounds into the lung. In rats, prolonged exposure to high concentrations of particles results in particle overload, a condition that is defined as overwhelming of macrophage mediated clearance by the deposition of particles at a rate that exceeds clearance capacity; however there is no evidence that this occurs in humans [15-16].

\section{B. Organic compounds}

A broad spectrum of organic compounds is adsorbed onto particles. Organic compounds present include alkanes, alkenes, aldehydes, monocyclic aromatic compounds, and polycyclic aromatic hydrocarbons (PAH) [7]. Aldehydes are potential carcinogens; with formaldehyde constituting $65-80 \%$ of aldehydes and acetylaldehyde and acrolein are the next most abundant [17]. Other potential carcinogens include benzene, butadiene, PAHs and nitro PAHs. A number of gaseous compounds (aldehydes, alkanes, alkenes, NOx and SOx) also induce respiratory tract irritation given sufficient exposure. Trace amounts of dioxins have been measured in heavy duty diesel exhausts [17]. 


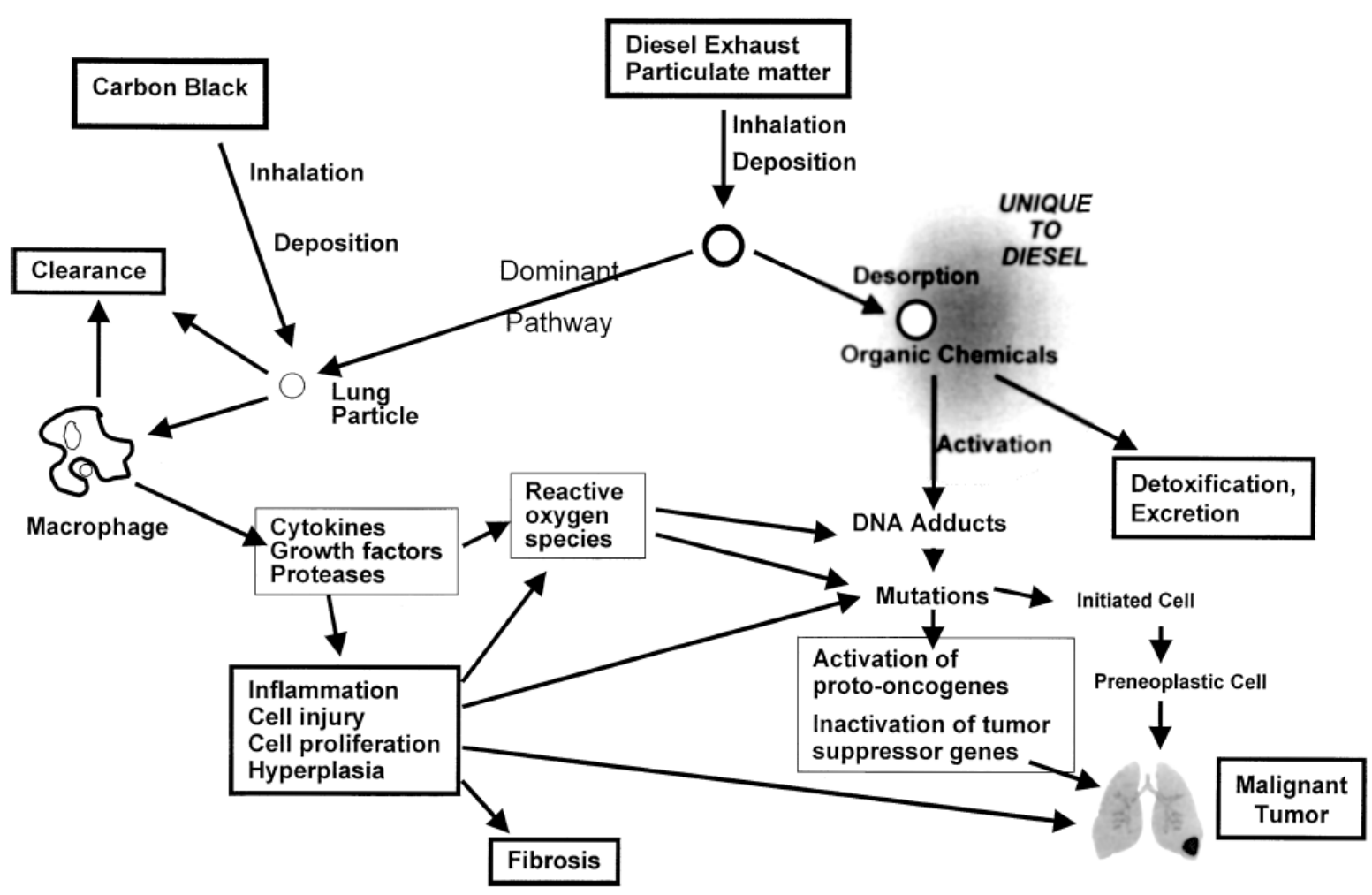

Figure 1. Proposed pathway of the health effects of diesel exhausts $[18,25]$. Two main pathways have been identified, the 'dominant pathway' indicates the effects related to particulate exposure, and the alternate pathway relates to gas phase components such as PAHs.

\section{C. "Fresh" versus "aged" diesel exhaust}

Newly emitted exhaust is termed "fresh" whereas exhaust that is more than 1 to 2 days old is referred to as "aged" [10]. Ageing can cause a reduction in toxicity, but also can increase in toxicity; hence its exact consequence on health effects is unclear. For example, PAH in fresh exhaust may be nitrated by atmospheric $\mathrm{NO}_{3}$ to form nitro PAHs, thus adding to toxicity; while PAH can also react with hydroxyl radicals in ambient air, leading to a reduction in the total PAH burden of diesel exhausts [10].

\section{HEALTH EFFECTS}

Available evidence indicates that there are human health hazards associated with exposure to diesel exhausts. The mechanism for the health effects of diesel exhaust can be considered through two main mechanisms [18]. Particulate matter is taken up by alveolar macrophages, this results in the development of reactive oxygen species and local inflammation. Both have the potential to lead to tumour formation. Prolonged inflammation increases the risk of DNA aberrations and tumour formation. Similarly reactive oxygen species can lead to form DNA adducts and mutations causing tumour formation. Alternatively, organic compounds, mainly in the gas phase, can react directly with cells, giving rise to DNA adducts, with subsequent mutations and tumour formation [19-20]. These two pathways have chiefly been derived from animal and in vitro studies, however definitive human studies are lacking.
The hazards include acute exposure-related symptoms, chronic exposure related noncarcinogenic effects, and lung cancer.

\section{A. Acute Effects}

Limited information is available on the health effects of acute exposure to diesel exhausts. However, on the basis of available human and animal evidence, it is concluded that acute exposure to diesel exhausts can cause acute irritation of the eye and throat; neurophysiologic symptoms including lightheadedness and nausea; and respiratory symptoms such as cough and phlegm [21-23]. There is also evidence for an immunologic effect - the exacerbation of allergenic responses to known allergens and asthma-like symptoms [24].

Cellular and mechanistic studies provide important information about how various particles and components related to air pollution interact with cells and cellular systems [7]. The studies describe inflammatory responses and provide support for the hypothesis that very small particles (ultrafine particles) are an especially harmful component, but suggest that the more coarse and intermediate-sized particulate matter are also important.

\section{B. Chronic Noncarcinogenic Effects}

Information from the available human studies is inadequate for a definitive evaluation of possible non-cancer health effects from chronic exposure to diesel exhausts. 
However, on the basis of extensive animal evidence, diesel exhausts pose a chronic respiratory hazard to humans [17]. Chronic-exposure, animal inhalation studies show a spectrum of dose-dependent inflammation and histopathological changes in the lung in several animal species, including rats, mice, hamsters, and monkeys [3, 25-26]. Human studies have demonstrated exacerbations of chronic bronchitis and chronic obstructive pulmonary disease [17].

\section{Carcinogenic Effects}

There is considerable evidence demonstrating an association between diesel exhaust exposure and increased lung cancer risk among workers in varied occupations where diesel engines historically have been used [27-28]. Most of the individual studies and all meta-analyses show an increased risk of lung cancer in occupations with exposure to diesel exhausts; however, exact exposure levels were not recorded [27]. Supporting evidence for the carcinogenic potential of diesel exhausts has been derived from in vitro and laboratory animal studies [13]. These demonstrated the mutagenic and chromosomal effects of diesel exhausts.

The long term health effects of diesel exhaust exposure are unclear. Although reasonable, no clear cumulative effect has been demonstrated, nor has any possible synergistic effect with other environmental carcinogens (e.g. cigarette smoke) been observed and compared with quantitative exposure data. The lack of exposure assessment in epidemiological studies is a major limitation and future studies should include quantitative exposure indicators such as element carbon.

\section{REFERENCES}

[1] IARC. IARC Monographs on the Evaluation of Carcinogenic Risks to Humans Volume 46 Diesel and Gasoline Engine Exhausts and Some Nitroarenes. 1989.

[2] NIOSH. Diesel exhaust. n.d. April 9, 2009.

[3] Hesterberg, T.W., et al., Non-cancer health effects of diesel exhaust: a critical assessment of recent human and animal toxicological literature. Crit Rev Toxicol, 2009. 39(3): p. 195-227.

[4] Hesterberg, T.W., et al., Critical review of the human data on short-term nitrogen dioxide (NO2) exposures: evidence for NO2 no-effect levels. Crit Rev Toxicol, 2009. 39(9): p. 743-81.

[5] Pronk, A., J. Coble, and P.A. Stewart, Occupational exposure to diesel engine exhaust: A literature review. Journal of Exposure Science and Environmental Epidemiology, 2009. 19(5): p. 443-457.

[6] Pope, C.A., 3rd, et al., Lung cancer, cardiopulmonary mortality, and long-term exposure to fine particulate air pollution. Jama, 2002. 287(9): p. 1132-41.

[7] Wichmann, H.E., Diesel exhaust particles. Inhalation Toxicology, 2007. 19: p. 241-244

[8] Wheatley, A.D. and S. Sadhra, Occupational exposure to diesel exhaust fumes. Ann Occup Hyg, 2004. 48(4): p. 369-76.

[9] Scheepers, P.T.J. and R.P. Bos, Combustion of Diesel Fuel from a Toxicological Perspective .2. Toxicity. International Archives of Occupational and Environmental Health, 1992. 64(3): p. 163-177.

[10] U.S. Environmental Protection Agency, Health Assessment Document For Diesel Engine Exhaust. 2002, the National Center for Environmental Assessment: Washington, DC. p. 669.

[11] Scheepers, P.T., et al., BIOMarkers for occupational diesel exhaust exposure monitoring (BIOMODEM)--a study in underground mining. Toxicol Lett, 2002. 134(1-3): p. 305-17.
[12] Ono-Ogasawara, M. and T.J. Smith, Diesel exhaust particles in the work environment and their analysis. Ind Health, 2004. 42(4): p. 389-99.

[13] Maier, K.L., et al., Health effects of ambient particulate matter Biological mechanisms and inflammatory responses to in vitro and in vivo particle exposures. Inhalation Toxicology, 2008. 20(3): p. 319-337.

[14] Mauderly, J.L., Health hazards of complex environmental exposures: A difficult challenge to inhalation toxicology. Inhalation Toxicology, 2006. 18(2): p. 137-141.

[15] Iwai, K., et al., Long-term inhalation studies of diesel exhaust on F344 SPF rats. Incidence of lung cancer and lymphoma. Dev Toxicol Environ Sci, 1986. 13: p. 349-60.

[16] Nikula, K.J., et al., Comparative Pulmonary Toxicities and Carcinogenicities of Chronically Inhaled Diesel Exhaust and Carbon-Black in F344 Rats. Fundamental and Applied Toxicology, 1995. 25(1): p. 80-94.

[17] Ris, C., US EPA health assessment for diesel engine exhaust: A review. Inhalation Toxicology, 2007. 19: p. 229-239.

[18] HEI, Diesel Exhaust: Critical Analysis of Emissions, Exposure, and Health Effects. A Special Report of the Institute's Diesel Epidemiology Working Group. 1995, Health Effects Institute: Boston.

[19] Liu, Y.Q., et al., In vitro genotoxicity of exhaust emissions of diesel and gasoline engine vehicles operated on a unified driving cycle. J Environ Monit, 2005. 7(1): p. 60-6.

[20] DeMarini, D.M., et al., Bioassay-directed fractionation and Salmonella mutagenicity of automobile and forklift diesel exhaust particles. Environmental Health Perspectives, 2004. 112(8): p. 814-819.

[21] Sydbom, A., et al., Health effects of diesel exhaust emissions. Eur Respir J, 2001. 17(4): p. 733-46.

[22] Krivoshto, I.N., et al., The toxicity of diesel exhaust: implications for primary care. J Am Board Fam Med, 2008. 21(1): p. 55-62.

[23] Riedl, M. and D. Diaz-Sanchez, Biology of diesel exhaust effects on respiratory function. J Allergy Clin Immunol, 2005. 115(2): p. 221-8; quiz 229.

[24] Carlsten, C., et al., Thrombotic markers in metabolic syndrome subjects exposed to diesel exhaust. Inhalation Toxicology, 2008. 20(10): p. 917-921.

[25] Hesterberg, T.W., et al., Carcinogenicity studies of diesel engine exhausts in laboratory animals: a review of past studies and a discussion of future research needs. Crit Rev Toxicol, 2005. 35(5): p. 379-411.

[26] Morgan, W.K., R.B. Reger, and D.M. Tucker, Health effects of diesel emissions. Ann Occup Hyg, 1997. 41(6): p. 643-58.

[27] Boers, D., et al., The influence of occupational exposure to pesticides, polycyclic aromatic hydrocarbons, diesel exhaust, metal dust, metal fumes, and mineral oil on prostate cancer: a prospective cohort study. Occup Environ Med, 2005. 62(8): p. 531-7.

[28] Bunn, W.B., et al., A reevaluation of the literature regarding the health assessment of diesel engine exhaust. Inhalation Toxicology, 2004. 16(14): p. 889-900. 